\title{
Minimizing the risk of perioperative stroke by clampless off-pump bypass surgery: a retrospective observational analysis
}

\author{
Michael Hilker*1, Mathias Arlt2, Andreas Keyser1, Simon Schopka', Alexander Klose1, Claudius Diez' and \\ Christof Schmid
}

\begin{abstract}
Objectives: Stroke is a devastating complication after coronary artery bypass grafting, occurring in $1.4 \%$ to $4.3 \%$ of patients. A major cause of stroke is cerebral embolization of aortic atheromatous debris or calcified plaques. This report analyzes the incidence of stroke in patients treated according to the clampless concept, i.e. avoiding side-clamping of the aorta, by means of off-pump coronary artery bypass surgery (OPCAB) in combination with the HEARTSTRING device.

Methods: During a period of 43 months (2005-2008), 412 consecutive patients were treated with the abovementioned method by one single surgeon. A minimum of one proximal aortal anastomosis was performed in each patient. Altogether, 542 proximal anastomosis were applied, each created by means of the HEARTSTRING device.

Results: The mean age of patients was 67+9.7 years, the predicted mortality 5.2\% (logistic EuroSCORE) and the observed mortality $1.9 \%$. Histories of preoperative neurological disorders or cerebrovascular diseases were documented in $15 \%$ of patients. The overall incidence of postoperative stroke was $0.48 \%$ in contrast to $1.3 \%$ according to the stroke risk score.
\end{abstract}

Conclusions: In accordance to previously published data, our results show that avoiding aortic side-clamping during OPCAB reduces postoperative stroke rates. The HEARTSTRING device is a safe option for creating proximal aortic anastomosis.

\section{Background}

Cardiac surgery is increasingly conducted in elderly patients with extensive comorbidities. Various advances in surgical techniques and anesthetic management have improved patient outcome after coronary artery bypass grafting (CABG); death rates in particular have declined during the past decade. Perioperative stroke is still one of the most devastating complications of coronary bypass surgery that not only causes high patient morbidity and mortality but also excessive economic costs [1-3]. Therefore, perioperative stroke remains a substantial problem. Various researchers have been able to identify preoperative variables as risk factors for the development of post-

\footnotetext{
* Correspondence: michael.hilker@klinik.uni-regensburg.de

1 Department of Cardiothoracic Surgery, University Medical Center Regensburg, Germany

Full list of author information is available at the end of the article
}

operative strokes [4-6]. Most of these factors, such as advanced age, peripheral vascular disease, diabetes, and dialysis, are closely related to the extension and development of atherosclerosis. Thus, the Northern New England Cardiovascular Disease Study Group developed a preoperative stroke prediction model that is also part of the current American College of Cardiology/American Heart Association guidelines for CABG [1,5]. Although various mechanisms have been recognized for the development of stroke in patients undergoing CABG, embolic dislodgment of atherosclerotic plaques due to surgical aortic manipulations remains the major cause of stroke. Hence, minimization or elimination of aortic manipulation results in reduced stroke rates. The use of off-pump CABG makes aortic cannulation and crossclamping unnecessary, whereas the use of saphenous vein or free arterial aortocoronary grafts still involves the risk of aor- 
tic embolism because of the tangential clamping maneuver during the construction of proximal anastomosis [79]. To overcome this problem, we routinely conducted HEARTSTRING supported proximal anastomosis during $O P C A B$ procedures following the clampless principle. Several authors have reported their first clinical experiences with the HEARTSTRING system [10-13]; our observations of 412 consecutive patients (542 proximal anastomosis) were made with particular regard to stroke rates.

\section{Methods}

\section{Study population}

From 2005 to 2008 (43 months), 412 consecutive patients undergoing off-pump CABG with a minimum of one proximal aortal anastomosis were prospectively enrolled into our analysis. All patients were treated according to the clampless off-pump procedure by means of the HEARTSTRING system. Each operation was conducted by one single surgeon.

The major outcome variable of this study was the occurrence of postoperative stroke. This complication was defined in accordance with the definition of stroke previously published by the Northern New England Cardiovascular Disease Study Group (NNECDSG). Stroke was defined as a new neurological deficit that appears and remains at least partially evident for more than 24 hours after its onset and occurs during or after the CABG procedure; moreover, strokes needed to be diagnosed before discharge. Furthermore, we distinguished between early stroke (intraoperatively or within 24 hours after surgery) and delayed stroke (more than 24 hours after surgery). Apart from clinical symptoms, diagnosis was confirmed by a neurologist and brain imaging. We neither included transient neurologic events or intellectual impairment nor states of confusion or irritation.

The preoperative risk of stroke was stratified according to the stroke risk score published in the ACC/AHA 2004 Guideline Update for Coronary Artery Bypass Graft Surgery.

\section{Anesthesia and surgical techniques}

To maintain normothermia, a heated mattress was placed underneath the patient, and intravenous fluids were warmed. Standardized anesthetic procedures include a low to intermediate dose of narcotics, inhalation drugs, paralytics, and intraoperative hemodynamic monitoring. A protocol to maintain normoglycemia was followed. We used Heparine $2 \mathrm{mg} / \mathrm{kg}$ to obtain an activated clotting time (ACT) of 400 seconds. ACT was measured every 20 minutes; top-up doses of heparin were administered if ACT was $<400$ seconds.

Each patient was operated on through a median sternotomy. All but a few patients had the most critical vessel, i.e. the left anterior descending (LAD) coronary artery, revascularized first. This procedure was followed by the revascularization of the lateral and inferior walls. Positioning of the heart and stabilization of the target vessels was achieved with vacuum assistance $\left(A C R O B A T^{\text {Tw }}\right.$ and $\mathrm{XPOSE}^{\mathrm{m}}$, Maquet Cardiopulmonary AG, Hechingen, Germany). Exposing lateral and inferior walls of the heart while maintaining stable hemodynamics was supported by means of a deep stitch and a sling as reported previously. Coronary shunts (AXIUS ${ }^{\mathrm{mm}}$, Maquet Cardiopulmonary AG, Hechingen, Germany) were routinely inserted whenever possible.

Intraoperative digital palpation of the aorta was used for locating atherosclerotic plaques; in patients with suspect aortic disease, we additionally used transesophageal echocardiography. Aortic atherosclerotic disease with epiaortic echocardiography was not intraoperatively assessed in this study. After completing distal anastomosis, we conducted proximal anastomosis on a disease-free segment of the aorta as assessed by palpation. First, we controlled the systolic aortic pressure $<100 \mathrm{mmHg}$, then a small incision was made with a scalpel to create a hole with a suitable and recyclable aortic punch. The coiled HEARTSTRING device was delivered through the aortic hole to establish a hemostatic seal against the inner aortic wall. Anastomosis were hand-sewn with 6-0 Prolene. Before the final tightening of the suture line, the device was uncoiled and removed. During the delivery and withdrawal process, hemostatic control was achieved by occlusion with a finger. No blower was used, neither for distal nor for proximal anastomosis. Postoperatively, each patient was administered acetylsalicylic acid. Patients with atrial fibrillation lasting more than 24 hours were routinely anticoagulated with heparin and warfarin.

\section{Data analysis}

Data were prospectively entered into a computerized database and retrospectively analyzed with a statistical package (STATISTICA; StatSoft, Inc). Results are reported as the mean \pm standard deviation. Chi-square test was used to analyse observed and expected frequency of mortality. Cumulative sum (CUSUM) technique was used in the assessment and monitoring of stroke among the study sample. Risk-adjusted CUSUM chart (cumulative sum chart) were constructed according to Grunkemeier at al. [14] as the $95 \%$ point-wise two-sided prediction limits. CUSUM technique is the most valuable and accepted tool in the assessment and monitoring of a process.

\section{Results}

Preoperative patient characteristics are listed in table 1. The calculated predictive stroke risk in our study population was $1.37 \% \pm 0.93$. A total of 1076 distal anastomosis 
Table 1: Demographic profile

\begin{tabular}{lrr}
\hline Variable & No. & (\%) \\
\hline Patients & 412 & \\
Age (y) & $67 \pm 9.7$ & \\
Female gender & 132 & $32.00 \%$ \\
Diabetes & 136 & $33.00 \%$ \\
Dialysis & 13 & $3.10 \%$ \\
Hypertension & 346 & $84.00 \%$ \\
PVD & 33 & $8.00 \%$ \\
Neurol. Disease & 62 & $15.00 \%$ \\
EF<40\% & 37 & $9.00 \%$ \\
Prior cardiac operation & 5 & $1.20 \%$ \\
Logistic EuroScore & & $5.20 \%$ \\
$\quad$ Prediction model & & $1.37 \%$ \\
$\quad$ for stroke & & \\
\hline
\end{tabular}

and 542 proximal anastomosis were conducted (Table 2). All proximal anastomosis were hand-sewn and supported with the HEARTSTRING device. No side-clamping of the ascending aorta was necessary to redo anastomosis in a conventional fashion. HEARTSTRING supported proximal anastomosis could be conducted in every patient, and the mean number was $1.3 \pm 0.4 .18$ devices $(3.3 \%)$ remained unused because of gaps within the seal caused by the rolling and loading process.

The predicted mortality of $5.2 \%$ was determined by means of the logistic EuroSCORE. The observed mortality was $1.9 \%$ and significantly lower than predicted $(\mathrm{p}=$ $0.002)$.

Major adverse cardiac, cerebrovascular, and renal events (i.e. death from any cause, stroke, myocardial infarction, repeat revascularization, and new dialysis) are summarized in Table 3. The overall incidence of stroke was $0.48 \%(n=2)$. Early stroke occurred in one patient and one delayed stroke was diagnosed. The two stroke patients showed evidence of a new cerebral infarction, which was confirmed by CT scanning. None of the two patients had reported a history of stroke before surgery. We constructed a risk-adjusted CUSUM chart for stroke $(\mathrm{n}=412)$. As shown in Figure 1, an downward slope indicates an excellent overall performance.

\section{Table 2: Surgical details}

\begin{tabular}{lcc}
\hline Variable & no. & (\%) \\
\hline Distal anastomosis & 1076 & \\
Proximal anastomosis & 542 & $97 \%$ \\
IMA & & 9
\end{tabular}

Table 3: Major adverse cardiac, cerebrovascular, and renal events

\begin{tabular}{lcc}
\hline Variable & no. & (\%) \\
\hline Stroke & 2 & $0.48 \%$ \\
Mortality & 8 & $1.90 \%$ \\
New dialysis & 9 & $2.20 \%$ \\
Re-intervention & 2 & $0.48 \%$ \\
Myocardial infarction & 7 & $1.70 \%$ \\
\hline
\end{tabular}

\section{Discussion}

The principal finding of this study is that clampless offpump CABG by means of the HEARTSTRING device can reduce the stroke rate in a large cohort of patients ( $0.48 \%$ observed vs. $1.3 \%$ predicted).

Neurological complications after CABG occur in up to $6.3 \%$ of patients [15], depending on the different aortic screening methods and surgical strategies as well as on how the deficit is defined $[2,4,8,16,17]$. The recently published SYNTAX trial has reported a $2.2 \%$ stroke rate after 12 month in the CABG group. Only $15 \%$ of CABG procedures were performed using OPCAB technique [18]. Information about the technique, i.e. how proximal anastomosis were constructed, was not given. In this study the percutaneous coronary intervention cohort showed a stroke rate of only $0.6 \%$. Despite the many advances made in cardiac surgery, postoperative stroke remains a problem, even if the incidence rate is low. Causative for the higher stroke rate in the CABG cohort of the SYNTAX trial could be addressed to the low percentage of OPCAB procedures. Further a reduction of stroke risk could be achieved by using clampless or no touch techniques. No

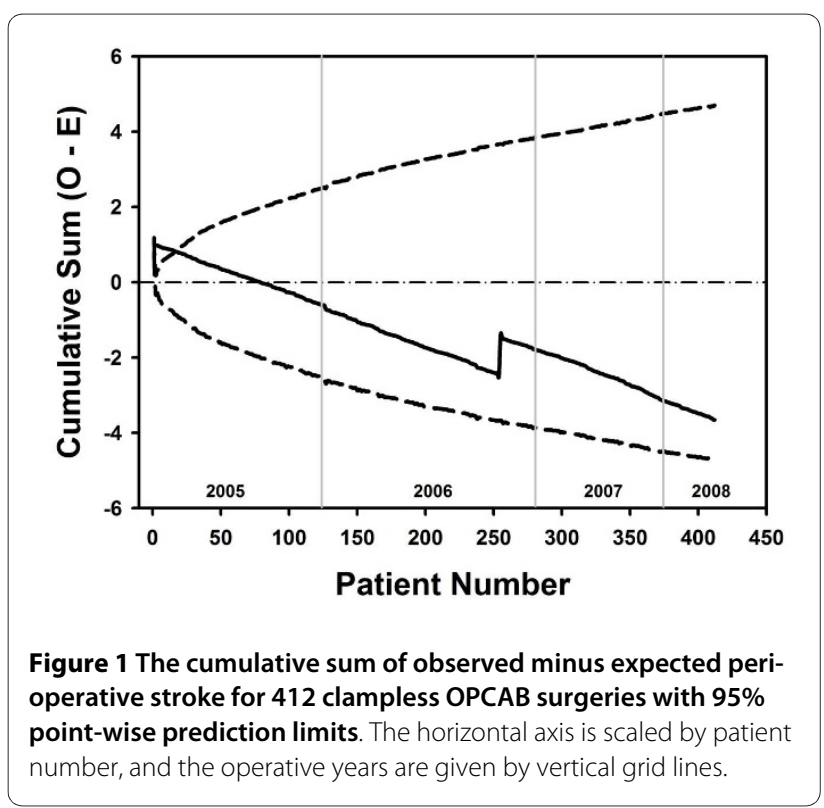


touch techniques avoiding any aortic manipulation can be achieved by using both internal thoracic arteries, gastroepiploic artery or Y- and T-graft constructions. This concept yields excellent results concerning stroke minimization. In case these techniques are not applicable due to limited graft inflow sources, the use of clampless proximal anastomosis devices, e. g. the HEARTSTRING device, play an important role. As shown in this analysis this concept yields a beneficial neurological outcome.

Neurological derangement after CABG has been attributed to hypoxia, embolism, hemorrhage, and metabolic abnormalities [1]. Proximal aortic atherosclerosis has been reported as the strongest predictor of stroke after CABG. This fact supports the theory that liberation of atheromatous material during manipulation of the aorta is the main cause of this complication. The embolic signals monitored by intraoperative intracranial Doppler ultrasoundsonography have clearly demonstrated that most embolisms detected during CABG procedure occur during cross-clamping and side-clamping $[7,19]$. Although embolic signals decrease during OPCAB procedures compared to on-pump bypass surgery. Free grafts anastomozed to the ascending aorta with a partial clamping during $\mathrm{OPCAB}$ procedures still comprises a possible source of stroke. Particularly the use of devices for supporting proximal anastomosis to avoid sideclamping has shown a significant reduction in the proportion of solid microembolisms detected with transcranial Doppler. Solid microembolism is the most important risk factor for intraoperative stroke [7]. Thus, it seemed reasonable that avoidance of aortic manipulation decreases stroke incidence. Therefore, our intention was to treat all OPCAB patients clampless, even while performing proximal aortic anastomosis.

At present, the best strategy seems to be to optimize cerebral perfusion and to minimize aortic manipulation to avoid macroembolic and microembolic damage $[20,21]$. Several authors have suggested that, once aortic atherosclerosis is identified, alternative strategies should be considered to prevent mobilization of aortic atheroma. These strategies include techniques such as groin or subclavian placement of the aortic cannulas, fibrillatory arrest without aortic cross-clamping, use of a single cross-clamp technique, modifying the placement of proximal anastomosis, all-arterial revascularization, or use of $\mathrm{T}$ and $\mathrm{Y}$ grafts $[8,10,17,22]$. Epiaortal ultrasound has been established as the technique of choice to screen the aorta for atherosclerosis and is particularly recommended for older patients. Furthermore, epiaortal ultrasound potentially influences a surgeon's decision [23].

The impact of partial aortic clamping on the incidence of stroke has been observed and described before. In particular, the subsequent risk has been shown to be compa- rable to aortic cannulation and cross-clamping as required for a cardiopulmonary bypass.

Limitations of this study include those inherent in retrospective single center analyses, even if data were collected prospectively. However, we do not believe that our findings are significantly affected by these limitations.

\section{Conclusions}

In conclusion, we showed that clampless off-pump surgery may reduce the incidence of stroke and proximal bypass aortic anastomosis may be safely conducted without side-clamping by means of the HEARTSTRING system.

Competing interests

The authors declare that they have no competing interests.

\section{Authors' contributions}

$\mathrm{MH}$ carried out follow ups and drafted the manuscript. MA participated in design and coordination of the study and helped to draft the manuscript. AnK coordinated the study and helped performing follow up studies. AlK performed follow up studies. SS performed follow up studies and helped to draft the manuscript. CD carried out statistical analysis LR Performed surgical ablations. CS conceived of the study, and participated in its design and coordination and helped to draft the manuscript. All authors read and approved the final manuscript.

\section{Author Details}

'Department of Cardiothoracic Surgery, University Medical Center Regensburg, Germany and 2Department of Anesthesiology, University Medical Center Regensburg, Germany

Received: 20 December 2009 Accepted: 25 March 2010 Published: 25 March 2010

\section{References}

1. Eagle KA, Guyton RA, Davidoff R, Edwards FH, Ewy GA, Gardner TJ, et al:: ACC/AHA 2004 guideline update for coronary artery bypass graft surgery: a report of the American College of Cardiology/American Heart Association Task Force on Practice Guidelines (Committee to Update the 1999 Guidelines for Coronary Artery Bypass Graft Surgery). Circulation 2004, 110(14):e340-437.

2. Cheng W, Denton TA, Fontana GP, Raissi S, Blanche C, Kass RM, et al:: Offpump coronary surgery: effect on early mortality and stroke. J Thorac Cardiovasc Surg 2002, 124(2):313-20.

3. Puskas JD, Winston AD, Wright CE, Gott JP, Brown WM III, Craver JM, et al.: Stroke after coronary artery operation: incidence, correlates, outcome, and cost. Ann Thorac Surg 2000, 69(4):1053-6.

4. Bucerius J, Gummert JF, Borger MA, Walther T, Doll N, Onnasch JF, et al:: Stroke after cardiac surgery: a risk factor analysis of 16,184 consecutive adult patients. Ann Thorac Surg 2003, 75(2):472-8.

5. Charlesworth DC, Likosky DS, Marrin CA, Maloney CT, Quinton HB, Morton $J R$, et al:: Development and validation of a prediction model for strokes after coronary artery bypass grafting. Ann Thorac Surg 2003, 76(2):436-43.

6. Likosky DS, Leavitt BJ, Marrin CA, Malenka DJ, Reeves AG, Weintraub RM, et al:: Intra- and postoperative predictors of stroke after coronary artery bypass grafting. Ann Thorac Surg 2003, 76(2):428-34. discussion 435

7. Guerrieri Wolf L, Abu-Omar Y, Choudhary BP, Pigott D, Taggart DP. Gaseous and solid cerebral microembolization during proximal aortic anastomosis in off-pump coronary surgery: the effect of an aortic sidebiting clamp and two clampless devices. J Thorac Cardiovasc Surg 2007, 133(2):485-93.

8. Bergman P, Hadjinikolaou L, Dellgren G, Linden J van der: A policy to reduce stroke in patients with extensive atherosclerosis of the ascending aorta undergoing coronary surgery. Interact Cardiovasc Thorac Surg 2004, 3(1):28-32 
9. Lev-Ran O, Braunstein R, Sharony R, Kramer A, Paz Y, Mohr R, et al:: Notouch aorta off-pump coronary surgery: the effect on stroke. J Thorac Cardiovasc Surg 2005, 129(2):307-13.

10. Biancari F, Mosorin M, Lahtinen J, Heikkinen J, Rasinaho E, Anttila V, et al.: Results with the Heartstring anastomotic device in patients with diseased ascending aorta. Scand Cardiovasc J 2006, 40(4):238-9.

11. Vicol C, Oberhoffer M, Nollert G, Eifert S, Boekstegers P, Wintersperger B, et al:: First clinical experience with the HEARTSTRING, a device for proximal anastomosis in coronary surgery. Ann Thorac Surg 2005, 79(5):1732-7. discussion 1737

12. Weber A, Reuthebuch $O$, Turina M: Guidant Heartstring: initial experience in OPCAB surgery. Heart Surg Forum 2005, 8(1):E4-8.

13. Kazui T, Doi H, Suzuki M, Okamoto T, Koshima R, Sugiki K, et al:: Initial clinical experience with the Heartstring. Jpn J Thorac Cardiovasc Surg 2006, 54(10):424-8.

14. Grunkemeier GL, Jin R, Wu Y: Cumulative sum curves and their prediction limits. Ann Thorac Surg 2009, 87(2):361-4.

15. Grossi EA, Bizekis CS, Sharony R, Saunders PC, Galloway AC, Lapietra A, et al: Routine intraoperative transesophageal echocardiography identifies patients with atheromatous aortas: impact on "off-pump" coronary artery bypass and perioperative stroke. JAm Soc Echocardiogr 2003, 16(7):751-5.

16. Bittner HB, Savitt MA, Ching PV, Ward HB: Off-pump coronary artery revascularization: ideal indication for patients with porcelain aorta and calcification of great vessels. J Cardiovasc Surg (Torino) 2003, 44(2):217-21.

17. Kim WS, Lee J, Lee YT, Sung K, Yang JH, Jun TG, et al:: Total arteria revascularization in triple-vessel disease with off-pump and aortic notouch technique. Ann Thorac Surg 2008, 86(6):1861-5.

18. Serruys PW, Morice MC, Kappetein AP, Colombo A, Holmes DR, Mack MJ et al:: Percutaneous coronary intervention versus coronary-artery bypass grafting for severe coronary artery disease. NEng/ J Med 2009, 360(10):961-72.

19. Motallebzadeh R, Bland JM, Markus HS, Kaski JC, Jahangiri M: Neurocognitive function and cerebral emboli: randomized study of onpump versus off-pump coronary artery bypass surgery. Ann Thorac Surg 2007, 83(2):475-82.

20. Goldman S, Sutter F, Ferdinand F, Trace C: Optimizing intraoperative cerebral oxygen delivery using noninvasive cerebral oximetry decreases the incidence of stroke for cardiac surgical patients. Heart Surg Forum 2004, 7(5):E376-81.

21. Nakamura M, Okamoto F, Nakanishi K, Maruyama R, Yamada A, Ushikoshi $S$, et al:: Does intensive management of cerebral hemodynamics and atheromatous aorta reduce stroke after coronary artery surgery? Ann Thorac Surg 2008, 85(2):513-9.

22. Trehan N, Mishra M, Kasliwal RR, Mishra A: Surgical strategies in patients at high risk for stroke undergoing coronary artery bypass grafting. Ann Thorac Surg 2000, 70(3):1037-45.

23. Rosenberger P, Shernan SK, Loffler M, Shekar PS, Fox JA, Tuli JK, et al:: The influence of epiaortic ultrasonography on intraoperative surgical management in 6051 cardiac surgical patients. Ann Thorac Surg 2008, 85(2):548-53.

doi: $10.1186 / 1749-8090-5-14$

Cite this article as: Hilker et al., Minimizing the risk of perioperative stroke by clampless off-pump bypass surgery: a retrospective observational analysis Journal of Cardiothoracic Surgery 2010, 5:14

\section{Submit your next manuscript to BioMed Central} and take full advantage of:

- Convenient online submission

- Thorough peer review

- No space constraints or color figure charges

- Immediate publication on acceptance

- Inclusion in PubMed, CAS, Scopus and Google Scholar

- Research which is freely available for redistribution

Submit your manuscript at www.biomedcentral.com/submit
C) Biomed Central 